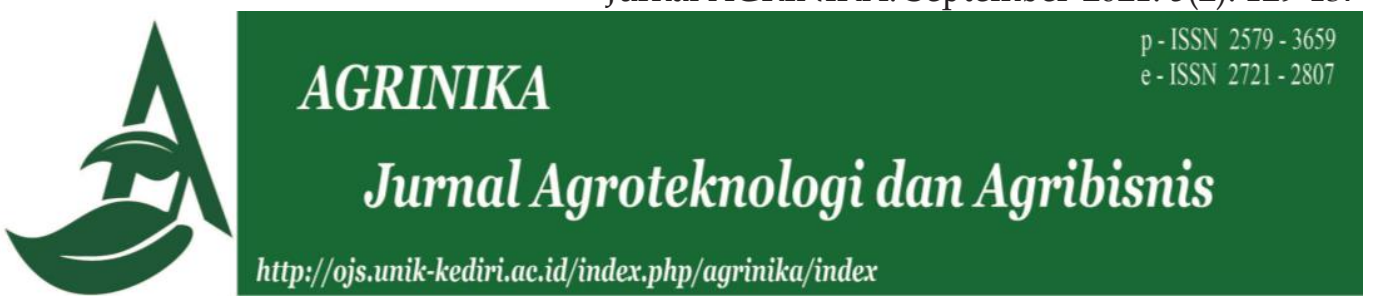

\title{
Pengaruh Kepemimpinan Terhadap Kinerja UMKM Kuliner di Kabupaten Jember Melalui Learning organization Sebagai Variabel Intervening
}

\author{
Muhammad Abdul Gofur ${ }^{1}$, Sri Sundari ${ }^{1 *}$, dan Tanti Kustiari ${ }^{1}$ \\ ${ }^{1}$ Program Studi Pascasarjana Agribisnis, Politeknik Negeri Jember, Jember, Indonesia \\ *Korespondensi: sri_sundari@polije.ac.id
}

Diterima 14 Juli 2021/ Direvisi 10 September 2021/ Disetujui 14 September 2021

\begin{abstract}
ABSTRAK
Usaha mikro, kecil dan menengah (UMKM) adalah kegiatan yang berisi tentang ekonomi produktif. Adapun pemiliknya adalah satu orang maupun organisasi yang tertuang dalam Undang - Undang Nomor 20 Tahun 2008. UMKM kuliner merupakan subsektor ekonomi kreatif yang mempunyai potensi besar. Permasalahan yang ada pada UMKM kuliner sangat banyak terutama permasalahan SDM yang dapat mempengaruhi kinerja, sehingga diperlukan SDM yang mempunyai jiwa kepemimpinan yang nantinya dapat menerapkan learning organization untuk peningkatan kinerja UMKM kuliner. Penelitian ini bertujuan mengetahui pengaruh kepemimpinan dan learning organization pada kinerja UMKM kuliner di Kabupaten Jember baik langsung maupun tidak langsung Jenis penelitian menggunakan deskriptif kuantitatif. Lokasi penelitian di Kabupaten Jember. Jumlah sampel penelitian 98 responden. Metode analisis data menggunakan analisis jalur. Hasil analisis kepemimpinan mempunyai pengaruh dalam mengembangkan learning organization. Kepemimpinan mempunyai peran dalam mengembangkan kinerja UMKM kuliner baik secara langsung maupun tidal langsung. Learning organization mempunyai pengaruh dalam mengembangkan kinerja UMKM kuliner. Hipotesis penelitian ini diterima semua.
\end{abstract}

Kata kunci : Kepemimpinan; Kinerja; Learning organization; UMKM kuliner

\section{ABSTRACT}

Micro, small and medium enterprises (MSMEs) are productive economic enterprises owned by individuals and entities as regulated in Law No. 20 of 2008. Culinary SMEs are sub-sectors of the creative economy that have great potential. The problems that exist in culinary SMEs are very many, especially HR problems that can affect performance. It is necessary to have human resources who have a leadership spirit who can later implement learning organizations to improve the performance of culinary SMEs. The purpose of the study was to determine the influence of leadership and learning organization on the performance of culinary SMEs in Jember Regency, either directly or indirectly. The research employed quantitative descriptive. The research location was in Jember Regency. The number of research samples was 98 respondents. The data analysis method used path analysis. The results of the leadership analysis influence in developing a learning organization. Leadership has a role in developing the performance of culinary SMEs both directly and indirectly. Learning organization influenced the development of the performance of culinary SMEs. All of the research hypotheses were accepted.

Keywords: Culinary SMEs; Leadership; Learning organization; Performance 


\section{PENDAHULUAN}

Kondisi ekonomi di dunia begitu dinamis sering dengan kemajuan teknologi dan informasi digital yang semakin canggih (Kementerian PPN/Bappenas, 2020). Hal tersebut perlu direspon dengan cepat oleh semua negara guna meningkatkan pertumbuhan ekonomi (Khoiri, 2019). Salah satunya, untuk meningkatkan pertumbuhan ekonomi jangka panjang yaitu dengan mendorong pertumbuhan usaha mikro, kecil dan menengah (UMKM) yang berbasis ekonomi kreatif (Noor dan Rahmasari). Usaha mikro, kecil dan menengah (UMKM) yaitu kegiatan ekonomi yang produktif yang dimiliki perorangan maupun badan usaha. Kriteria UMKM menurut UU No. 20 Tahun 2008 yaitu 1) Usaha Mikro adalah usaha yang memiliki kekayaan bersih Rp50 juta dan penjualan setiap tahun Rp300 juta. 2) Usaha Kecil adalah usaha yang memiliki kekayaan bersih Rp50 juta - Rp500 juta dan penjualan setiap tahun Rp300 juta - Rp2,5 milyar 3) Usaha Menengah adalah usaha yang memiliki kekayaan bersih Rp500 juta Rp10 milyar dan penjualan setiap tahun Rp2,5 milyar - Rp50 milyar.

UMKM di Indonesia sudah terbukti dalam menghadapi krisis ekonomi pada tahun 1998. UMKM mampu bertahan dan berkembang hingga sekarang ini (Suci et al., 2017).. Pengembangan UMKM berbasis ekonomi kreatif sangatlah diperlukan, mengingat perubahan ekonomi yang cepat menuntut pelaku UMKM bisa beradaptasi dengan perubahan tersebut (Ishworo, 2015). Ekonomi kreatif di Indonesia sudah lama dicanangkan, terlihat pada Inpres 6/2009 tahun 2009 tentang dukungan dalam pengembangan ekonomi kreatif tahun 2009-2015 (Purnomo, 2016). Ekonomi kreatif di Indonesia mempunyai potensi yang sangat besar, dimana Indonesia memiliki ragam budaya, suku, agama dan lain-lain. Hasil survei dari Bekraf dan BPS (2016) kontribusi ekonomi kreatif pada tahun 2015 terhadap PDB Nasional sebesar 7,38\% (852 triliun rupiah), menyerap tenaga kerja sebesar $13,90 \%$ (15,9 juta tenaga kerja) dan nilai ekspor sebesar 12,88\% (US\$ 19,4 miliar).

Kuliner merupakan salah satu subsektor ekonomi kreatif yang mempunyai potensi besar. Subsektor kuliner tercatat menyumbang $41,69 \%$ PDB dari ekonomi kreatif di Indonesia (Bekraf dan BPS, 2016). Kata kuliner berasal dari komoditas yang berkaitan dengan masakan dan kegiatan konsumsi makanan dan minuman (Akbar \& Pangestuti, 2017)

Jumlah pelaku UMKM kuliner yang terdaftar di Diskopum Kabupaten Jember mulai tahun 2011 sampai dengan 2019 tercatat ada 2101 UMKM kuliner (Diskopum Kabupaten Jember, 2019). Akan tetapi jumlah UMKM kuliner di Kabupaten Jember tidak selalu meningkat setiap tahunnya. Terbukti pada tahun 2019 UMKM kuliner yang terdaftar di Diskopum Kabupaten Jember hanya 122 UMKM kuliner, berbeda pada tahun sebelumnya yang berjumlah 311 UMKM (Diskopum Kabupaten Jember, 2019). Hal ini menandakan masih banyak permasalahan UMKM kuliner di Kabupaten Jember.

Penurunan tersebut akibat dari SDM yang tidak siap dengan perkembangan teknologi digital. Kemajuan teknologi informasi dan 
komunikasi berbasis digital merubah gaya berbisnis UMKM kuliner, dari bisnis konvensional menjadi lebih modern (Sidabutar, 2014). Seperti halnya memesan makan yang dulu harus datang langsung ke tempat kuliner, sekarang cukup dengan smartphone bisa pesan secara online. Faktor lain yang menyebabkan penurunan tersebut dikarenakan adanya persaingan diantara pelaku kuliner baik yang baru maupun lama (Kasus et al., 2020). Para pesaing mempunyai keunggul dalam segi modal, pemasaran, pelayanan, manajemen, dan SDM, sehingga mudah untuk beradaptasi dengan permasalahan yang ada (S. Almasik et al.). Permasalahan utama yang dihadapi UMKM yaitu keterbatasan sumber daya manusia (SDM) (Agustina et al., 2020). Sumber daya manusia (SDM) merupakan faktor internal yang dapat mempengaruhi kinerja UMKM (Lanang et al., 2014).

Kepememimpinan merupakan salah satu kunci suksesnya suatu organisasi (Siti Nur Aisah, 2020). Peran seorang pemimpin dalam UMKM kuliner mempunyai andil sangat besar (Ramdani, 2019). Maju mundurnya usaha tergantung pada kebijakan yang dipilih pemimpin, untuk itu perlu adanya jiwa kepemimpinan bagi pelaku UMKM kuliner (Faizaty \& Rivanda, 2019). Pemimpin yang tidak kompeten dalam menjalankan usaha kuliner akan berdampak negatif, dikarenakan usaha kuliner menuntut pelakunya selalu kreatif, inovatif dan berani mengambil resiko (Aldania \& Niswah, 2021). Hal ini menunjukkan pentingnya kepemimpinan dalam organisasi (Kiwang et al., 2015).

Pengetahuan merupakan aset yang berharga untuk menghadapi persaingan (Ferdian \& Devita, 2020). Pemimpin juga perlu mengembangkan pengetahuan dan keterampilan anggota dalam organisasi, sehingga perlu adanya learning organization (Hendrawan et al., 2018). Pemberdayaan dan peran pemimpin dalam pembelajaran sebagai keterampilan penting bagi pemimpin untuk learning organization (Aji et al., 2020). Keunggulan kompetitif organisasi bisa dibangun dan dipertahankan melalui strategi mengelola perubahan yaitu dengan membangun learning organization (Bayu Aji et al., 2020). Organisasi pembelajaran menggambarkan bahwa pembelajaran adalah prasyarat atas keberhasilan terjadinya sebuah perubahan dan kinerja organisasi (Lisanty et al., 2020).

Berdasarkan uraian diatas, rumusan masalah UMKM kuliner di Kabupaten Jember yaitu 1) Apakah kepemimpinan berpengaruh terhadap learning organization?, 2) Apakah kepemimpinan berpengaruh terhadap kinerja?, 3) Apakah learning organization berpengaruh terhadap kinerja? dan 4) Apakah kepemimpinan berpengaruh terhadap kinerja melalui learning organization?. Tujuan penelitian ini untuk mengetahui pengaruh kepemimpinan terhadap kinerja UMKM kuliner di Kabupaten Jember melalui learning organization. Manfaat bagi pemerintah Kabupaten Jember sebagai masukan untuk mengambil kebijakan terkait pengembangan UMKM kuliner, bagi pelaku UMKM kuliner sebagai solusi dan saran untuk mengembangkan usaha

\section{METODE PENELITIAN}

Penelitian ini dilaksanakan mulai tanggal 3 Desember 2020 - 24 Maret 2021 di Kabupaten Jember. Penelitian ini menggunakan pendekatan kuantitatif 
deskriptif. Lokasi penelitian berada di seluruh kecamatan di Kabupaten Jember.

Populasi penelitian ini berjumlah 2101 UMKM kuliner dan sampel ditentukan dengan metode slovin nilai error $10 \%$ berjumlah 98 UMKM kuliner. Teknik pengambilan sampel menggunakan propotional sampling, sehingga sampel bisa merata. Variabel penelitian ini yaitu kepemimpinan sebagai variabel eksogen (Muizu et al.), variabel learning organization sebagai variabel intervening (Lukito et al.),, dan kinerja sebagai variabel endogen (Minuzu ,2010).
Teknik pengumpulan data yang digunakan dalam penelitian menggunakan metode wawancara. Metode analisis data pada penelitian ini menggunakan analisis jalur (path analys) dengan bantuan program SPSS IBM 25. Persamaan regresi linier sebagai berikut:

$Z=a+b_{1} X+\varepsilon$

$Y=a+b_{1} X+b_{2} Z+\varepsilon$

Keterangan:

$$
\begin{array}{ll}
\mathrm{Y} & =\text { Kinerja } \\
\mathrm{X} & =\text { Kepemimpinan } \\
\mathrm{Z} & =\text { Learning Organization } \\
\mathrm{b} 1 & =\text { Koefisien Regresi } \\
\mathrm{b} 2 & =\text { Koefisien Regresi } \\
\mathrm{a} & =\text { Kostanta } \\
\varepsilon & =\text { Error }
\end{array}
$$

Tabel 1 Sampel masing-masing kecamatan

\begin{tabular}{clrrllrr}
\hline No & Kecamatan & UMKM & Sampel & No & Kecamatan & UMKM & Sampel \\
\hline 1 & Ajung & 62 & 3 & 18 & Panti & 49 & 2 \\
2 & Ambulu & 112 & 5 & 19 & Patrang & 286 & 13 \\
3 & Arjasa & 28 & 1 & 20 & Puger & 18 & 1 \\
4 & Balung & 14 & 21 & Rambipuji & 43 & 2 \\
5 & Bangsalsari & 32 & 1 & 22 & Semboro & 4 & 1 \\
6 & Gumukmas & 54 & 2 & 23 & Silo & 67 & 3 \\
7 & Jelbuk & 47 & 2 & 24 & Sukorambi & 43 & 2 \\
8 & Jenggawah & 72 & 3 & 25 & Sukowono & 48 & 2 \\
9 & Jombang & 11 & 1 & 26 & Sumberbaru & 21 & 1 \\
10 & Kalisat & 33 & 27 & Sumberjambe & 7 & 1 \\
12 & Kaliwates & 314 & 14 & 28 & Sumbersari & 318 & 14 \\
13 & Kencong & 11 & 1 & 29 & Tanggul & 19 & 1 \\
14 & Ledokombo & 58 & 3 & 30 & Tempurejo & 29 & 1 \\
15 & Mayang & 2 & 1 & 31 & Umbulsari & 14 & 1 \\
16 & Mumbulsari & 18 & 1 & 32 & Wuluhan & 137 & 6 \\
17 & Pakusari & 100 & 5 & & & & \\
\hline & Total & $\mathbf{9 9 8}$ & $\mathbf{4 7}$ & & & $\mathbf{1 1 0 3}$ & $\mathbf{5 1}$ \\
\hline
\end{tabular}

Sumber : Data diolah, 2020

\section{HASIL DAN PEMBAHASAN}

Kabupaten Jember merupakan salah satu daerah yang berada di wilayah Tapal Kuda Provinsi Jawa Timur. Kabupaten Jember berbatasan dengan Kabupaten Lumajang, Kabupaten Probolinggo, Kabupaten Bondowoso dan Kabupaten Banyu- wangi. Luas wilayah Kabupaten Jember sebesar $3.375 \mathrm{~km}^{2}$ dengan jumlah penduduk di tahun 2019 sebesar 2,538,921 jiwa. Kabupaten Jember terbagi secara administrasi menjadi 31 Kecamatan dan 248 Desa.

UMKM kuliner di Kabupaten Jember didominasi oleh usia produktif yaitu berusia antara 21 sampai 30 tahun 
sebesar 52,04\%. Mayoritas pelaku UMKM kuliner di Kabupaten Jember didominasi perempuan sebanyak $52,5 \%$, dengan jenjang pendidikan $47 \%$ lulusan SMA sederajat, dan mayoritas usaha yang dimiliki sudah berjalan 1-2 tahun. Hasil tersebut menunjukkan bahwa mayoritas pelaku UMKM kuliner di Kabupaten Jember didominasi perempuan dengan umur produktif, mempunyai pendidikan SMA sederajat dan lama usaha yang dirintis minimal 12 tahun.
Pada Tabel 2. menunjukan hasil pengujian hipotesis hubungan langsung. Pengujian signifikansi hipotesis terpenuhi apabila $t_{\text {hitung }}$ lebih besar dari $t_{\text {tabel }}$ sebesar 1,98 yang menunjukkan terdapat pengaruh variabel bebas terhadap variabel terikat. Pada Tabel 3 menunjukkan hasi ringkasan pengujian hubungan langsung dan tidak langsung antara variabel bebas, variabel terikat dan variabel mediasi.

Tabel 2. Hasil pengujian hipotesis

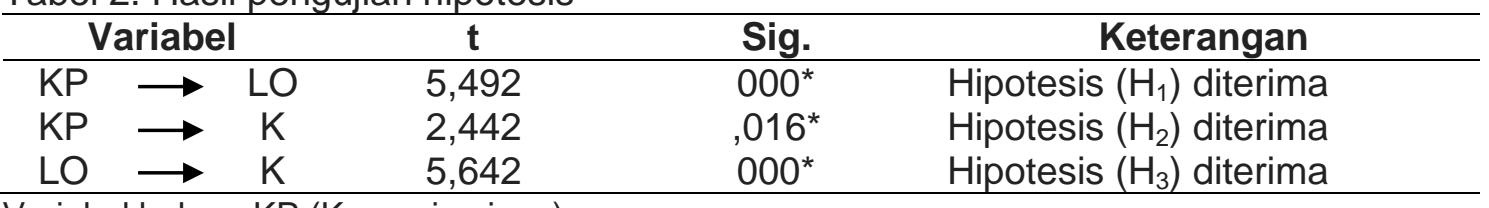

Variabel bebas: KP (Kepemimpinan)

Variabel terikat: LO (Learning Organization) dan K (Kinerja)

Keterangan: *) Signifikan

Sumber: Data primer diolah, 2021

Tabel 3. Hasil pengujian hubungan langsung dan tidak langsung

\begin{tabular}{cccccc}
\hline \multicolumn{2}{c}{ Variabel } & & \multirow{2}{*}{$\mathbf{R}^{2}$} & \multicolumn{2}{c}{ Pengaruh Hubungan } \\
\cline { 4 - 6 } & & & Langsung & Tidak Langsung \\
\hline $\mathrm{KP}$ & $\rightarrow$ & $\mathrm{LO}$ & 0,239 & $0,489^{*}$ & $0,248^{*}$ \\
$\mathrm{KP}$ & $\rightarrow$ & $\mathrm{K}$ & & $0,220^{*}$ & \\
$\mathrm{LO}$ & $\rightarrow$ & $\mathrm{K}$ & 0,415 & $0,508^{*}$ & \\
\hline
\end{tabular}

Variabel bebas: KP (Kepemimpinan)

Variabel terikat: LO (Learning Organization) dan K (Kinerja)

Keterangan: *) Signifikan

Sumber: Data primer diolah, 2021

Hasil uji hipotesis tabel 2 menunjukkan bahwa semua hipotesis berpengaruh positif dan signifikan. Hal tersebut meunjukkan bahwa kepemimpian mempunyai pengaruh terhadap learnig organization dan kinerja. Learning organization berpengaruh positif terhadap kinerja. Hasil pengujian hubungan terlihat pada Tabel 3, menunjukkan bahwa pengaruh tidak langsung kepemimpinan terhadap kinerja lebih besar dibandingkan pengaruh langsung kepemimpinan terhadap kinerja, yang artinya hipotesis keempat diterima.

Pengaruh Kepemimpinan Terhadap Learning Organization

Kepemimpinan merupakan hal yang penting dalam organisasi. Menurut Robbins dan Judge (2013) kepemimpinan sebagai kemampuan untuk mempengaruhi suatu kelompok terhadap pencapaian visi atau 
serangkaian tujuan. Hasil pengujian tabel 2 menunjukkan bahwa hipotesis pertama kepemimpinan berpengaruh langsung dan signifikan terhadap learning organization diterima. Artinya semakin baik kepemimpinan seseorang dalam UMKM kuliner, maka akan besar pula pengaruhnya pada learning organization UMKM kuliner di Kabupaten Jember.

Menurut Sange dalam Rijal (2016) kepemimpinan mempunyai tiga peran yang penting untuk membangun learning organization yaitu pemimpin sebagai desainer, sebagai guru, dan sebagai pelayan. Adanya pemimpin yang visioner dan inovatif dapat memberi peluang pegawai untuk belajar kembali. Memberikan fasilitas untuk belajar dan kemudahan informasi merupakan salah satu wujud dukungan pemimpin kepada pegawainya, agar pegawai mampu berfikir global dan kreatif. Pemimpin mampu memberikan perhatian dan mendengarkan aspirasi pegawai salah satu bentuk pengahrgaan bagi pegawainya. Hal ini sesui dengan pendapat Mirkamali et al (2011) pemimpin memfasilitasi pembelajaran dengan cara membimbing, membangun kreasi, dan hubungan antar kelompok. Penelitian ini sesuai dengan penelitian yang dilakukan Rofiati et al (2015) dan Hendriani et al (2018) bahwa kepemimpinan berpengaruh terhadap learning organization.

Pengaruh Kepemimpinan Terhadap Kineria

Kepemimpinan adalah suatu kemampuan untuk mempengaruhi orang lain atau suatu kelompok, sehingga

\section{Pengaruh Learning organization} Terhadap Kinerja mereka mau melakukan kehendak pemimpin untuk mencapai tujuan kelompok yang sangat berpengaruh terhadap kinerja. Kepemimpinan mempengaruhi kinerja UMKM kuliner di Kabupaten Jember terlihat pada hipotesis kedua. Hasil penghitungan hipotesis kedua diterima. Hal ini menunjukkan kepemimpinan yang diterapkan di UMKM kuliner di Kabupaten Jember berpengaruh secara signifikan terhadap kinerja UMKM kuliner di Jember.

Menurut Aboyassin \& Abood, (2013) dalam Rofiati et al (2015) bahwa kepemimpinan yang efektif berdampak positif pada kinerja individu dan organisasi. Pemimpin UMKM kuliner mampu mengarahkan visi misi dengan benar kepada anggotanya, sehingga tercapainya tujuan perusahaan yaitu keuntungan yang besar. Sifat pemimpin yang jujur dan amanah bisa menjadi panutan bagi pegawainya, sehingga menumbuhkan loyalitas dan kepercaryaan pada pegawainya. Pemimpin yang inovatif dapat menciptakan produk baru, sehingga kepetingan pertumbuhan pasar dan penjualan dapat terpenuhi. Penerapan kepemimpinan yang dilakukan pelaku UMKM kuliner selama ini berpengaruh terhadap kinerja UMKM kuliner di Kabupaten Jember. Hal ini sejalan dengan penelitian yang dilakukan oleh Trang (2013), Ritawati (2013), Nanda (2017), Sumual (2015), Rofiati et al (2015), Hendriani et al (2018) dan Muizu et al (2019), yang menyatakan bahwa kepemimpinan berpengaruh signifikan terhadap kinerja.

Learning organization merupakan suatu organisasi yang endorong anggotanya untuk terus menerus belajar meningkatkan kemampuan, pola pikir 
baru dan wawasan baru. Hasil hipotesis ketiga diterima artinya learning organization secara langsung mempunyai pengaruh signifikan terhadap kinerja. Hal ini menunjukkan learning organization yang dilaksakan pelaku UMKM kuliner di Kabupaten Jember mempunyai pengaruh yang signifikan terhadapa kinerja UMKM kuliner di Kabupaten Jember.

Hal ini membuktikan bahwa proses belajar yang dilakukan pelaku UMKM kuliner di Kabupaten Jember secara langsung dapat mempengaruhi jalannya kinerja UMKM kuliner. Dampak dari penerapan learning organization bagi kinerja UMKM kuliner dapat dirasakan dengan meningkatnya pertumbuhan penjualan, modal, tenaga kerja, pasar dan laba pada perusahaan. Learning organization menggambarkan bahwa pembelajaran adalah prasyarat atas keberhasilan terjadinya sebuah perubahan dan kinerja organisasi Che Rose et al. (2009). Penelitian ini didukung oleh Sampe (2012), Sirait et al (2015), Safitri et al (2018), Hendriani et al (2018) dan Gaushasti (2020) bahwa learning organization berpengaruh terhadap kinerja organisasi.

Pengaruh Kepemimpinan Terhadap Kineria Melalui Learning organization

Hasil hipotesis keempat menunjukkan adanya pengaruh tidak langsung dan signifikan kepemimpian terhadap kinerja melalui learning organization. Hal ini terlihat pada Tabel 3 hubungan tidak langsung lebih besar dibandingkan hubungan langsung. Hal ini menunjukkan dengan learning organization yang diterapkan pada UMKM kuiner di Kabupaten Jember mampu memediasi kepemimpinan terhadap kinerja UMKM kuliner. Artinya, kepemimpinan yang diterapkan pada
UMKM kuliner di Kabupaten Jember mampu mengarahkan pegawainya untuk belajar kembali yang pada akhirnya mempengaruhi kinerja UMKM kuiner di Kabupaten Jember.

Kepemimpinan merupakan faktor penting dalam menjalankan sebuah organisasi, dimana dengan kepemimpinan yang baik akan memberikan dampak bagi lingkungan dalam organisasi tersebut. Kepemimpinan yang tepat dapat menginspirasi pekerja untuk mengikuti pemimpinannya, dengan begitu pemimpin dapat mengarahkan anggota pada visi misi perusahan. Usaha tersebut akan tercapai jiaka pegawai mau mengambil kesempatan belajar kembali. Setelah mendapatkan informasi dan pengetahuan baru, pegawai dapat diandalkan untuk meningkatkan kinerja UMKM kuliner.

$\mathrm{Hal}$ tersebut sesuai pernyataan Johnson (2002) dalam Rijal (2016) menganggap bahwa visi pemberdayaan dan peran pemimpin dalam pembelajaran sebagai keterampilan penting bagi pemimpin untuk learning organization. Hipotesis tersebut sesuai dengan penelitian yang dilakukan Rofiati et al (2015), Hendriani et al (2018) dan Gaushasti (2020) bahwa kepemimpinan berpengaruh tidak langsung terhadap kinerja organisasi melalui learning organization.

\section{KESIMPULAN}

Adapun kesimpulan yang dapat disampaikan antara lain :

1. Faktor pemimpin UMKM memiliki daya perubahan yang kuat terhadap learning organization dan kinerja.

2. Learning organization juga memiliki daya kuat dengan kinerja perusahaan 
Muhammad Abdul Gofur, Pengaruh Kepemimpinan Terhadap...

3. Learning organization mampu memediasi atau menjadi perantara antara kepemimpinan dengan kinerja.

\section{DAFTAR PUSTAKA}

Agustina, T., Gerhana, W., \& , S. (2020). The Effect of Locus of Control, Learning, and Adversity Quotient towards Micro Business Success (Study on Entrepreneurship under Foster Group of the Banjarmasin Regional Government). Journal of Wetlands Environmental Management. https://doi.org/10.20527/jwem.v8i1. 215

Aji, S. B., Herlina, H., \& Purnomo, B. H. (2020). Application Of Business Model Canvas In Production And Marketing Of Solog (Analogue Sausage). Food ScienTech Journal. https://doi.org/10.33512/fsj.v2i1.813 7

Akbar, A., \& Pangestuti, E. (2017). Peran Kuliner Dalam Meningkatkan Citra .Destinasi.Pariwisata Taman Nasional Bromo Tengger Semeru. Jurnal Administrasi Bisnis S1 Universitas Brawijaya.

Aldania, A., \& Niswah, F. (2021). Strategi Kompetitif Melalui Program Pahlawan Ekonomi Dalam Pemberdayaan Umkm Pasca Pandemi Covid-19 (Studi pada Pemerintah Kota Surabaya). Publika.

https://doi.org/10.26740/publika.v9n 2.p137-148

Almasik, S., Atmadja, A. R., \& Pariyatin, Y. (2021). Rancang Bangun Aplikasi Forum Diskusi Usaha
Mikro Kecil dan Menengah Berbasis Web. Jurnal Algoritma. https://doi.org/10.33364/algoritma/v. 17-2.168

Bayu Aji, S., Sutiknjo, T. D., \& Dinawati, E. (2020). Peranan Penyuluh Pertanian Terhadap Keberhasilan Penerepan Sistem Tanam Padi Jajar Legowo di Desa Pagung Kecamatan Semen Kabupaten Kediri. Jurnal Agrinika: Jurnal Agroteknologi Dan Agribisnis. https://doi.org/10.30737/agrinika.v4i 2.1075

Faizaty, N. E., \& Rivanda, N. O. (2019). Pengaruh Gaya Kepemimpinan Otokratis terhadap Perilaku Inovatif Karyawan UMKM Batik Ghatot Tuban. Jurnal Ekonomi Dan Manajemen.

Ferdian, A., \& Devita, A. R. (2020). Pengaruh Budaya Organisasi Dan Knowledge Management Terhadap Kinerja Karyawan. Jurnal Penelitian IPTEKS.

https://doi.org/10.32528/ipteks.v5i2. 3657

Hendrawan, A., Yulianeu, A., Sucahyawati, H., \& Indriyani, I. (2018). Pengembangan Kompetensi UMKM Dengan Pembelajaran Organisasi. INOBIS: Jurnal Inovasi Bisnis Dan Manajemen Indonesia. https://doi.org/10.31842/jurnalinobis.v1i4.53

Ishworo, W. (2015). Peran Umkm Dalam Perekonomian Indonesia, Implementasi \& Kendalanya. Jurnal Publikasi Universitas Tulung Agung. 
Kasus, S., Pt, P., \& Burni, M. (2020). Strategi UMKM Dalam Menghadapi Persaingan Bisnis Global. Journal Management, Business, and Accounting.

Kementerian PPN/Bappenas. (2020). Laporan Perkembangan Ekonomi Indonesia dan Dunia Triwulan III Tahun 2020.

Www.Bappenas.Go.ld.

Khoiri, Q. (2019). Globalisasi Dan Respon Pesantren. Nuansa. https://doi.org/10.29300/nuansa.v12 i1.2170

Kiwang, A. S., Pandie, D. B. W., \& Gana, F. (2015). Analisis Kebijakan dan Efektivitas Organisasi. JKAP (Jurnal Kebijakan Dan Administrasi Publik).

https://doi.org/10.22146/jkap.7535

Lanang, I. P. E. S., Kirya, I. K., \& Cipta, I. W. (2014). Analisis Faktor-Faktor Yang Mempengaruhi Kinerja Usaha Mikro Kecil Dan Menengah (UMKM) Di Kabupaten Bangli. EJournal Bisma Universitas Pendidikan Ganesha.

Lisanty, N., Aji, S. B., \& Pamujiati, A. D. (2020). Budidaya Perikanan Skala Kecil: Studi Kasus Ternak Ikan Gurami (Osphronemus Gouramy)Di Desa Mojosari Kecamatan Kras Kabupaten Kediri. Jurnal Agrinika: Jurnal Agroteknologi Dan Agribisnis.

https://doi.org/10.30737/agrinika.v4i 1.796

Minuzu, Musran. (2010). Pengaruh Faktor-Faktor Eksternal dan Internal Terhadap Kinerja Usaha Mikro dan Kecil (UMK) di Sulawesi
Selatan. Jurnal Manajemen dan Kewirausahaan, Vol.12, No. 1, Maret 2010:33-41

Noor, H. C. M., \& Rahmasari, G. (2018). Esensi Perencanaan Bisnis yang Memadai Bagi Usaha Mikro Kecil dan Menengah ( UMKM ). Jurnal Abdimas BSI.

Purnomo, R. A. (2016). Ekonomi Kreatif : Pilar Pembangunan Indonesia. In Ziyad Visi Media.

Ramdani, R. (2019). Kepemimpinan Transformasional (Studi Kasus Dinas Koperasi Dan UMKM Kota Semarang). The Indonesian Journal Of Politics And Policy (IJPP). https://doi.org/10.35706/ijpp.v111.16 43

Sidabutar, V. T. P. (2014). Peluang dan Permasalahan yang Dihadapi UMKM Berorientasi Ekspor. Balai Besar Pendidikan Dan Pelatihan Ekspor Indonesia, Ditjen PEN, Kemendag RI.

Siti Nur Aisah. (2020). Pengaruh Gaya Kepemimpinan Terhadap Kinerja Karyawan. Bulletin of Management and

Business. https://doi.org/10.31328/bmb.v1i2.1 00

Suci, Y. R., Tinggi, S., \& Ekonomi, I. (2017). Perkembangan UMKM (Usaha Mikro Kecil Menengah) di Indonesia. Jurnal IImiah Fakultasi Ekonomi. 